\title{
Psychosocial Impact of COVID-19 on Malta's Elderly
}

\author{
By Michael Galea*, Alexei Sammut ${ }^{ \pm}$, Paulann Grech ${ }^{*}$, \\ Josianne Scerri ${ }^{+}$Daniela Calleja Bitar \& Stephania Dimech Sant ${ }^{\natural}$
}

A global pandemic raises concerns among each human being. However, this is a more pressing reality among vulnerable groups, such as the elderly. It is the scope of this study to investigate the potential psycho-social risks that COVID-19 presents to the elderly in Malta, with a particular focus on their holistic mental health status. Public data, gathered and published by Richmond Foundation Malta, a local NGO, was analyzed during an eleven-month period (2020/2021) during eight different time-points. Two findings were highlighted: first, the roll out of vaccines is still not a room for complacency. This pandemic experience has been, and still is, a learning experience especially to authorities on how to respond to the needs of society, particularly the vulnerable groups. Secondly, results show that generally, a healthy life-style was maintained among most elderly in this study. However, virtual contact with family and friends declined over time, virtual religious programs were maintained, while social isolation increased. This study addressed the importance of attending to the holistic wellness of the elderly during critical times like the pandemic, be they the physical, social, emotional, and religious realities of this population. Furthermore, closing the digital divide was found as a truly relevant realm that calls for more serious considerations. Hopefully, this assists the elderly both in self-care and their concerns about other-care as well. A number of practical recommendations were presented.

Keywords: COVID-19, elderly, older adults, psychosocial impact, well-being, mental health

\section{Introduction}

The COVID-19 pandemic has drastically altered most people's lifestyle, globally. It has been described as "a portal" (Roy 2020), with significant consequences that have touched most realms of human life: emotional (Montemurro 2020); psycho-social balance of people (Brooks et al. 2020); psychological distress of whole countries (Qiu et al. 2020) employment and the world economy (Gangopadhyaya and Garrett 2020); while risking millions of jobs (Riley 2020). The emergence of vaccines has undoubtedly been great news worldwide that raised hopes that the pandemic's reach will eventually be contained. However, this must still be noted with caution, because the reality of COVID-19 out there remains hindered by many factors, from still to be discovered mutations, to the fact that many populations have grown tired of the safety

\footnotetext{
*Senior Lecturer, University of Malta, Malta.

${ }^{ \pm}$Lecturer, University of Malta, Malta.

${ }^{\star}$ Senior Lecturer, University of Malta, Malta.

${ }^{+}$Associate Professor, University of Malta, Malta.

'Chief Operations Officer, Richmond Foundation, Malta.

${ }^{\diamond}$ Chief Executive Officer, Richmond Foundation, Malta.
} 
protocols that had to be implemented (Mukhtar 2020). There are still too many unknowns about this pandemic that life may never be quite the same.

Mental health services had to be adjusted to the ever-changing and evolving situation, particularly with regards to older adults who had to be isolated and/or quarantined (Yang et al. 2020). A number of consequences were related to this reality (Armitage and Nellums 2020), with higher degrees of mental health problems including suicide mortality (Reger et al. 2020).

As Van Jaarsveld (2020) clearly found, the effects of the pandemic among the elderly populations is a true case for closing the digital divide, particularly in view of self-isolation. This may entail the redesigning of websites for older adults (Patsoule and Koutsabasis 2014), in order to target this vulnerable population with a familiar and easy to use technology (Leonardi et al. 2008).

Hollander and Carr (2020) have even suggested new and challenging ways to push forward telemedicine in critical times such as the present pandemic. This may endorse a more advanced virtual health care where help and assistance are given to elderly patients in their own homes, rather than the traditional way, whereby individuals were expected to seek help themselves (Webster 2020). Despite the fact that this adjustment may face resistance by some quarters, as each change normally does, it is high time that national strategies are put in place to help alter older people's attitudes and perceptions, in view of possible pandemics that may rise in the future (Mitzner et al. 2010).

Figure 1. Daily New Confirmed COVID-19 Cases

(7-day rolling average. Due to limited testing, the number of confirmed cases is lower that the true number of infections.)

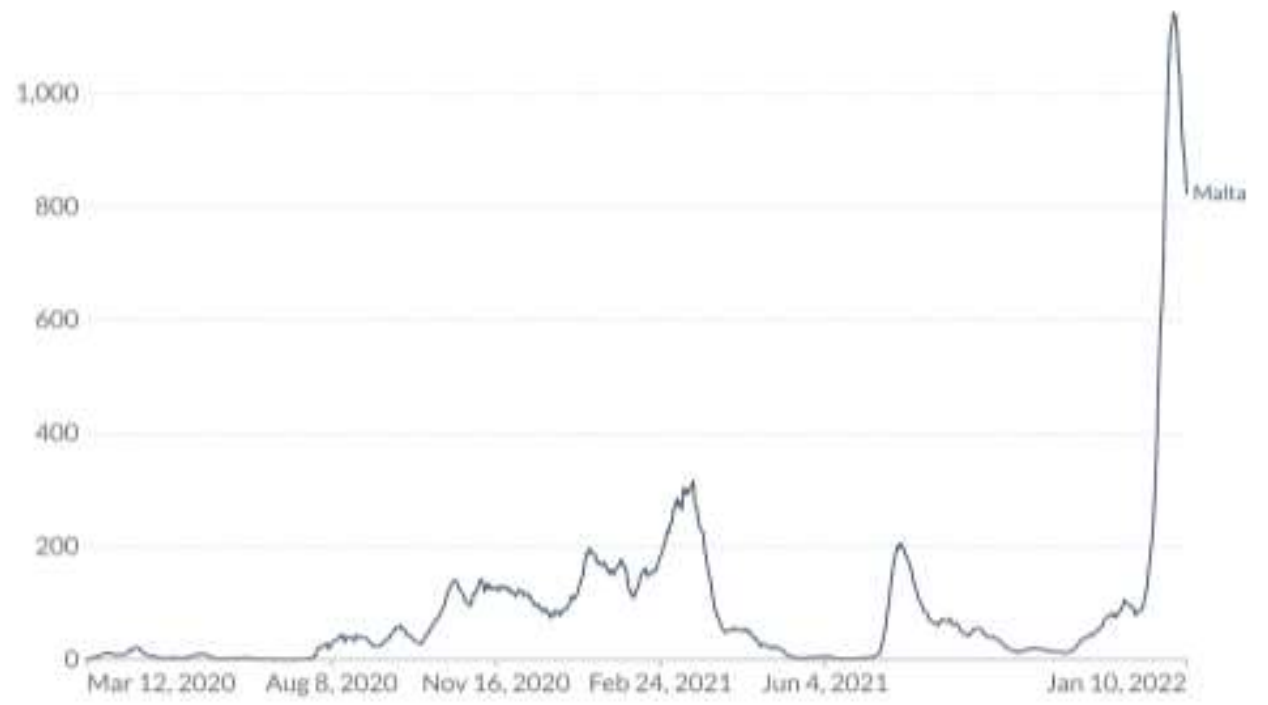

Source: Johns Hopkins University CSSE COVID-19 Data.

Figure 2 shows the daily confirmed COVID-19 deaths in Malta to date.

According to the WHO Weekly Epidemiological Update (11th January 2022), there have been more than 305 million cases, over 5.4 million deaths, and with more than 9 trillion vaccines given, globally. In Malta, there have been over 60 
thousand cases (Figure 1), with 488 deaths (Figure 2), and with over 1.1 million vaccines administered, meaning that $112 \%$ of the population has received at least 2 doses (Global Change Data Lab 2022). While vaccinations are obviously ongoing, segments of populations around the world who keep resisting them remain the most vulnerable.

Figure 2. Daily New Confirmed COVID-19 Deaths

(For some countries the number of confirmed deaths is much lower that the true number of deaths. This is because of limiting testing and challenges in the attribution of the cause of death.)

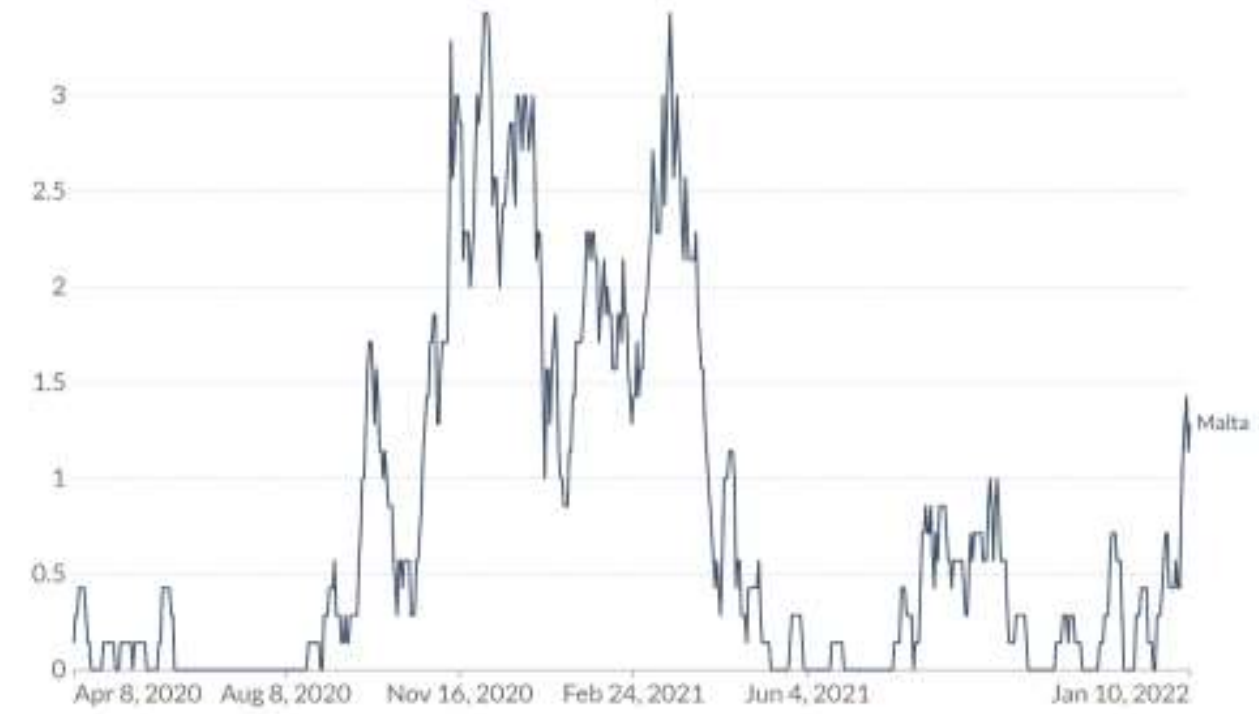

Source: Johns Hopkins University CSSE COVID-19 Data.

It is natural that during such critical times, our attention falls on the most vulnerable groups within society. It is the scope of this study to focus therefore on the holistic well-being status of older adults in view of the COVID-19 pandemic. The elderly as a group face vulnerability through a number of factors that need to be evaluated in such times, like: a) psycho-social issues including loneliness (Cacioppo et al. 2002), social isolation (Gerst-Emerson and Jayawardhana 2015); and mental health wellness overall (Yang et al. 2020); b) advanced age, and c) problems in accessing health care, amongst other issues.

Authorities and policy makers need to attend to a number of aspects that may be important in assisting and safeguarding the elderly in view of this and similar pandemics. Misconceptions about the pandemic (such as that somehow one is immune from contracting the disease) need to be addressed by proper and timely educational systems (Okaka and Omondi forthcoming). A sound and adjustable social policy stems from this reality, and as shown in studies done by Papanikos (2020), such policies do work and should be sought for varied reasons, including the fact that population size and the economy do play a role in explaining variations in deaths per capita, in EU countries. Another point regards the possibility that with so much overwhelming news constantly emerging, there is high risk of missing out the mental health status of the elderly particularly during times of a pandemic (Philip and Cherian 2020). 
The present COVID-19 pandemic has been consistently associated with direct and indirect influences on people's mental health, and this with particular reference to vulnerable groups such as the elderly (Hu et al. 2020, Haider et al. 2020). Thus, the objective of this preliminary study was to seek the psycho-social ramifications of the pandemic on the holistic status of the elderly in Malta, and consider which recommendations may be best applicable to the local situation.

\section{Method}

Anonymous data was collected by Richmond Foundation Malta (RFM), a local NGO, which has been monitoring the holistic and mental wellbeing of a cross-section of the population locally. Descriptive frequencies are made publicly available on the Foundation's website. For the purpose of this study, data collected during an eight-month continuum (April 2020 - March 2021) was analyzed. Each of the eight Time intervals $(\mathrm{T} 1=$ April 2020, T2 $=$ June 2020, T3 = August 2020, $\mathrm{T} 4=$ October 2020, T5 = December 2020, T6 = January 2021, T7 = February 2021, and T8 = March 2021) included data from 500 participants. With a $95 \%$ confidence interval and a 5\% margin of error, this study was totally anonymous, including a clear briefing on the nature of the study. Participants were free to participate and could quit the study with no adversarial consequences. Participation in the study implied consent. Time 1 extended during the first wave of the pandemic while Time 3 saw the start of the second wave, in Malta. Participants' age ranged from 16 - 85 years old. This study focused on data gathered on participants who were within the $65+$ year cohort. Gerontologists classify this age boundary as the young-old (Lee et al. 2018).

\section{Findings}

The study had slightly more females (53\%) than males. Moreover, the mean percentage of respondents who qualified for our study's purposes $(65+$ year old age bracket) was $17 \%$ across all time intervals. Table 1 presents some descriptive statistics on the study's older adults' daily perceptions and feelings with regards to their own and others' safety and health, in view of the COVID-19 pandemic.

Findings clearly outline the increase of anxiety and concerns among the elderly along the progression of the pandemic. This stems from worries about one's own well-being amidst the unpredictable future. It was felt across the board that respondents keenly noticed poor hygiene styles among those around them, which emphasizes the special care humans give to health when faced with a crisis. This also means that being careful for oneself may not be enough in such challenging and taxing situations. Moreover, respondents' concerns related also about the well-being and safety of their families and close friends. The respondents' need to seek out help and to share their own concerns was widely noted in this study's results. In addition to reaching out to others, respondents oriented their attention to seek help from higher powers as well. Solace in prayer 
was strongly indicated by the elderly across all time intervals, with the 55-64 age cohort reported a $21 \%$ increase across all time waves.

Table 1. Perceptions (\%) of Respondents on Critical Areas of Their Well-Being by Age-Ranges

\begin{tabular}{|l|c|c|c|c|c|c|c|c|c|}
\hline & T1 & T2 & T3 & T4 & T5 & T6 & T7 & T8 \\
\hline Felt depressed (daily) & \multicolumn{7}{|l|}{$\mid$} \\
\hline 16-24 year old & 23 & 04 & 19 & 03 & 10 & 10 & 07 & 15 \\
\hline 25-34 year old & 27 & 14 & 12 & 10 & 06 & 11 & 10 & 11 \\
\hline 35-44 year old & 22 & 04 & 05 & 08 & 07 & 10 & 08 & 15 \\
\hline 45-54 year old & 18 & 02 & 05 & 08 & 02 & 06 & 04 & 06 \\
\hline 55-64 year old & 15 & 05 & 09 & 05 & 09 & 04 & 05 & 06 \\
\hline 65+ year old & 14 & 01 & 14 & 08 & 01 & 09 & 12 & 10 \\
\hline Felt lonely (daily) & \multicolumn{7}{|l|}{} \\
\hline 16-24 year old & 20 & 07 & 11 & 03 & 09 & 13 & 07 & 17 \\
\hline 25-34 year old & 15 & 06 & 04 & 07 & 11 & 08 & 06 & 09 \\
\hline 35-44 year old & 11 & 03 & 08 & 06 & 06 & 13 & 08 & 13 \\
\hline 45-54 year old & 12 & 05 & 08 & 07 & 05 & 09 & 07 & 05 \\
\hline 55-64 year old & 06 & 09 & 05 & 04 & 10 & 04 & 04 & 10 \\
\hline 65+ year old & 11 & 05 & 14 & 07 & 06 & 08 & 08 & 08 \\
\hline Healthy Diet (daily) & \multicolumn{7}{|l|}{$\mid$} \\
\hline 16-24 year old & 27 & 41 & 38 & 35 & 37 & 27 & 45 & 34 \\
\hline 25-34 year old & 29 & 39 & 39 & 29 & 43 & 25 & 47 & 28 \\
\hline 35-44 year old & 27 & 35 & 35 & 43 & 35 & 39 & 58 & 29 \\
\hline 45-54 year old & 36 & 49 & 53 & 46 & 56 & 49 & 70 & 40 \\
\hline 55-64 year old & 57 & 54 & 56 & 65 & 58 & 58 & 61 & 50 \\
\hline 65+ year old & 59 & 44 & 70 & 57 & 72 & 61 & 71 & 58 \\
\hline
\end{tabular}

T1: April 2020, T2: June 2020, T3: August 2020, T4: October 2020, T5: December 2020, T6: January 2021; T7: February 2021; T8: March 2021.

Table 2 presents further descriptive frequencies of the participants' solace in meditation, private prayer, virtual contact with close others, attending to house chores (during lockdown periods), social isolation, loneliness and other relevant variables.

Table 2. Averages (\%) of Key Variables across all Age-Cohorts among the 8-pt Study

\begin{tabular}{|l|c|c|c|c|c|c|c|c|}
\hline & T1 & T2 & T3 & T4 & T5 & T6 & T7 & T8 \\
\hline Cleaned up the house & 29 & 31 & 31 & 31 & 35 & 34 & 44 & 27 \\
\hline Virtual contact w family/friends & 37 & 33 & 31 & 27 & 29 & 25 & 37 & 28 \\
\hline Found solace in prayer & 20 & 22 & 29 & 27 & 32 & 28 & 43 & 31 \\
\hline Meditated & 04 & 05 & 09 & 05 & 09 & 05 & 09 & 03 \\
\hline Could not get going & 19 & 05 & 08 & 05 & 05 & 06 & 07 & 07 \\
\hline Life required an unusual effort & 15 & 08 & 12 & 08 & 10 & 08 & 07 & 13 \\
\hline More sensitive than usual & 18 & 07 & 12 & 08 & 06 & 09 & 08 & 09 \\
\hline Felt socially isolated & 40 & 23 & 26 & 26 & 29 & 32 & 34 & 40 \\
\hline Stayed away from other people & 39 & 47 & 62 & 54 & 57 & 55 & 70 & 62 \\
\hline
\end{tabular}

T1: April 2020, T2: June 2020, T3: August 2020, T4: October 2020, T5: December 2020, T6: January 2021; T7: February 2021; T8: March 2021. 
Indicative to this study are variables related to interpersonal contact with others during semi-lockdown times. Virtual contact with family and/or friends declined by time. Reasons for this may be varied. One must assess whether the old adults grew weary and tired of using social media platforms for their virtual contact with their dear ones, and if this were so, whether this occurred because perhaps such platforms are not user-friendly, or maybe they need updating and more interactive versions.

More worrying is the fact that increasingly more participants stayed away from people. This could have been done in order to help protect oneself from unnecessary risk of infection. Nevertheless, one by-product of this situation is that individuals feel more isolated. In fact, participants' feelings of being socially isolated remained constant across the time intervals under our study.

During any crisis, such as the COVID-19 pandemic, self-care presents a complex challenge to vulnerable populations. Although it is generally hoped that each sector within society abides by certain healthy lifestyles, this may not always be possible in all spheres, especially when considering that the resources, both at the macro (national) and micro level (family dynamics, elderly and other persons who live alone, etc.) could be easily strained excessively. Findings from this survey indicate that the picture may not be so straightforward. Commendable is the result that respondents aged $65+$ heightened their healthy life-style attitudes (physical exercise, keeping a routine, healthy diet), together with increased vigilance and maintained their regular house-chores.

COVID-19 had mixed effects on respondents' own emotions. On one hand, it is promising to note a steady increase in feelings of happiness and hopefulness. This was furthered by a decrease of fear and depression over time. Intriguingly, loneliness increased more with age. Loneliness is borne from many variables, including social isolation, which has been found in research globally as one of the main consequences of this pandemic (Cao et al. 2020, Mukhtar 2020). Restless sleep is closely related to this aspect. Restless sleep showed fluctuating results, with a dip towards the last two waves. This could be a result of the roll out of vaccines, especially to the elderly, during that time. Participants' own rating of happiness, albeit quite steady across all time waves, saw a sharp decrease from Time 7 to the latest Time 8 .

\section{Discussion}

This study highlights a number of outcomes that require special mention. As COVID-19 pandemic progressed, with more research, news analysis and caution about its dangerous effects, more concern and anxiety became refined. The roll-up of vaccines did surely help; however, vigilance should never be abated because such emergencies warrant no room for complacency.

Another key result that emerged was that the handling of the COVID-19 situation locally was first perceived as laxed. This was during the first wave of the pandemic, when people were deeply affected and also scared with what was happening in nearby Italy and surrounding countries, where the full bite of the 
pandemic started being mostly felt. Eventually, the elderly's perception on the local authorities' handling of the situation improved, especially from Time 5 to date. It must be noted that in Malta, the authorities sanctioned no full lockdowns, but only two partial ones, while striving successfully to attend meticulously to the economic wheel of the country. Moreover, considering that this global pandemic entailed that most governments had to learn how to deal with circumstances as time progressed, it was a given that an amount of anxiety was incorporated in this process. As a natural consequence, an element of lack of peace of mind in the general population was involved. Research found that personal worries and anxiety about the pandemic was correlated to a decline in trust in societal institutions, which resulted in more acute mental health problems and loneliness (Van Tilburg et al. 2020).

Further analysis of the results presents two domains which relate to human self-defense responses during difficult times, relating to our survival instincts. Azar (2010) strongly points at the fact that humans search for meaning-making variables especially in unpredictable times and uncertain days. Thus, results recommended the intrapersonal (innermost) and the interpersonal (relational) domains.

Because pandemics and similar global afflictions have a significant impact on psychosocial realities (Banerjee 2020), it is reasonable that a crucial human reaction would address the intrapersonal or innermost domain. It is part of our survival strategy that when faced with a threat, we naturally become more attentive to our own needs. Findings from this study point to this realm. For example, an increase in self-care tendencies was strongly recognized (including more physical exercise, maintaining a routine, adhering to a healthy diet, house chores, etc.). This could have been a way to cope with some mental health effects resulting from an increase in loneliness, due to social isolation, especially during the semi-lockdown periods.

The second major reality resulting from our human response when faced with existential threats relates to the interpersonal or relational domain. Results from this study point at the respondents' concern about one's own and others' well-being in such critical times. One's relationship outside oneself extends even to resorting to supernatural help (prayer and meditation). A sizable $45 \%$ of respondents found solace and strength in their faith or through prayer. Galea (2012) has highlighted the relevance of spirituality in critical moments, especially when this reality is deemed important and relevant by the affected individuals. Religious services streamlined on the internet and on a number of social media platforms are another way how elderly may also keep up-to-date with their own religious activities and virtually in touch with their respective religious communities. Staying socially connected, even remotely, is crucial. It is perhaps a great irony in life, that it is in times of distress and crises that humans reach out to others (for help and solace), whereas in times of material wellness, the opposite may be true!

Health anxiety, panic, adjustment disorders, depression, chronic stress, and insomnia are the major offshoots. Misinformation and uncertainty may give rise to mass hysteria. Banerjee (2020) suggested that lessons from earlier pandemics like SARS have proved that regular telephonic counseling sessions, healthy contact 
with the family, relevant, correct, and updated information, caring for general medical and psychological needs, and respecting their personal space and dignity are important components of mental health care in the elderly.

\section{Recommendations from the Findings}

Considering the vulnerability that elderly individuals have to face, particularly in such difficult times, a number of suggestions are in place.

First, it is of paramount importance that society learns from such tragic instances in order to be well equipped should or when similar events occur in the future. Society must be ready to address the needs and holistic wellbeing of the vulnerable groups within it, especially the elderly (Li et al. 2014, Mukhtar 2020). This pandemic's impact excused no one. The elderly's mental health was seriously impacted, and thus calls for better attention in the future (Cao et al. 2020, Douglas 2020). Quarantine was especially challenging (Brooks et al. 2020), resulting in depression and at times even suicide (Rajkumar 2020, Djernes 2006). Indeed, no one was spared from the emotional footprint (Montemurro 2020), but the elderly and other vulnerable groups deserve more assiduous consideration in such critical times. Addressing the mental well-being of the elderly entail routine and structure (in bedtime, waking times, meal times, activity times, and "online" times, staying physically and cognitively active, amongst others), while paying attention to issues that may preclude this process. An overwhelming exposure to media news may be one such problem. Education in this aspect is called for. Checking in regularly on the aging adults in one's life is another key suggestion that no society should ignore (Grech et al. 2020, Scerri et al. 2021). Attention against the use, or rather misuse, of alcohol as self-medication, is also warranted (Schonfeld and Dupree 1994).

Secondly, the COVID-19 pandemic among the elderly is truly a case for closing the digital divide (Van Jaarsveld et al. 2020). More education and appropriate information will hopefully disentangle the intricacies and challenges inherent in social media and internet as a whole. The present COVID-19 pandemic has challenged people everywhere to learn to make better use of the internet technology in view of challenges hardly ever seen before in our times (Patsoule and Koutsabasis 2014). Results from this study go even further, and point at the high relevance and importance of making familiar such social media platforms where religiosity is concerned. Considering the fact that the geriatric population increasingly adds up to a sizeable proportion of the general population, a fact in Malta as in many other countries, and also acknowledging that this cohort in Malta is very religious, thus availing such religious technology to them, regularly, augurs better to their holistic well-being. This component will surely complement the fact that internet technology is shared progressively in all spheres of society, to make it more important and relevant than ever (Leonardi et al. 2008). 


\section{Conclusion}

In conclusion, the psycho-social impact on the elderly by the COVID-19 in Malta is similar to that found elsewhere as pointed out in research. Higher anxiety and stress levels were associated with a higher need to take care of one's own needs, and creative ways to relate to others (family members and friends), which is a natural tendency. Finally, this study calls for a more holistic attention to the needs of older adults within society, with a number of practical recommendations. A society's true colors are evident in how it attends and responds holistically to its members' needs, particularly the vulnerable groups within it.

\section{Acknowledgments}

The Authors wish to thank Richmond Foundation Malta for their assistance in this study.

\section{References}

Armitage R, Nellums LB (2020) COVID-19 and the consequences of isolating the elderly. Lancet Public Health 5(5): e256.

Azar B (2010) A reason to believe. The Monitor (American Psychological Association) 41(11): 52-53.

Banerjee D (2020) The impact of COVID-19 pandemic on elderly mental health. International Journal of Geriatric Psychiatry 35(12): 1466-1467.

Brooks SK, Webster RK, Smith LE, Woodland L, Wessely S, Greenberg N, et al. (2020) The psychological impact of quarantine and how to reduce it: rapid review of the evidence. Lancet 395(Feb): 912-920.

Cacioppo JT, Hawkley LC, Crawford LE, Ernst JM, Burleson MH, Kowalewski RB, et al. (2002) Loneliness and health: potential mechanisms. Psychosomatic Medicine 64(3): 407-417.

Cao W, Fang Z, Hou G, Han M, Xu X, Dong J, et al. (2020) The psychological impact of the COVID-19 epidemic on college students in China. Psychiatric Research 287(May): 112934.

Djernes JK (2006) Prevalence and predictors of depression in populations of elderly: a review. Acta Psychiatric Scandinavia.113(5): 372-387.

Douglas M (2020) Mitigating the wider health effects of COVID-19 pandemic response. British Medical Journal 369(Apr): m1557.

Galea M (2012) Studying the incremental validity of family environment among Maltese university students with past mental trauma. Pastoral Psychology 61(1): 211-220.

Gangopadhyaya A, Garrett AB (2020) Unemployment, health insurance, and the COVID19 recession. SSRN Electron Journal.

Gerst-Emerson K, Jayawardhana J (2015) Loneliness as a public health issue: the impact of loneliness on health care utilization among older adults. American Journal of Public Health 105(5): 1013-1019.

Global Change Data Lab (2022) Malta COVID-19 Situation (2022): What has been the impact of the pandemic? England and Wales: Our World In Data, Global Change Data Lab. Available at: https://ourworldindata.org/coronavirus/country/malta. 
Grech P, Scerri J, Cilia Vincenti S, Sammut A, Galea M, Calleja Bitar D, et al. (2020) Service users' perception of the therapeutic milieu in a mental health rehabilitation unit. Issues in Mental Health Nursing 41(11): 1019-1026.

Haider II, Tiwana F, Tahir SM (2020) Impact of the COVID-19 pandemic on adult mental health. Pakistan Journal of Medical Science 36(May): S90-S94.

Hollander JE, Carr BG (2020) Virtually perfect? Telemedicine for COVID-19. New England Journal of Medicine 382(Apr): 1679-1681.

$\mathrm{Hu}$ W, Su L, Qiao J, Zhu J, Zhou Y (2020) COVID-19 outbreak increased the risk of schizophrenia in aged adults. In Chinaxiv.org. Preprint.

Lee SB, Oh JH, Park JH, Choi SP, Wee JH (2018) Differences in youngest-old, middleold, and oldest-old patients who visit the emergency department. Clinical and Experimental Emergency Medicine 5(4): 249-255.

Leonardi C, Mennecozzi C, Not E, Pianesi F, Zancanaro M (2008) Designing a familiar technology for elderly people. Gerontechnology 7(2).

Li D, Zhang D, Shao J, Qi X, Tian L (2014) A meta-analysis of the prevalence of depressive symptoms in Chinese older adults. Archives of Gerontology Geriatric. 58(1): 1-9.

Mitzner TL, Boron JB, Fausset CB, Adams AE, Charness N, Czaja SJ, et al. (2010) Older adults talk technology: technology usage and attitudes. Computerized Human Behavior 26(6): 1710-1721.

Montemurro N (2020) The emotional impact of COVID-19: from medical staff to common people. Brain Behavioral Immunization 87(Jul): 23-24.

Mukhtar S (2020) Psychological impact of COVID-19 on older adults. Current Medical Research Practice 10(4): 201-202.

Okaka FO, Omondi P (forthcoming) Knowledge, Attitude and Practices (KAP) towards COVID-19 among older people living in informal settlements in Nairobi city, Kenya. Athens Journal of Social Sciences. Available at: https://www.athensjournals.gr/social/ 2021-4430-AJSS-SOS-Okaka-05.pdf.

Papanikos GT (2020) The demographics of COVID-19 in the EU. Athens Journal of Social Sciences 7(4): 279-290.

Patsoule E, Koutsabasis P (2014) Redesigning websites for older adults: a case study. Behavioral Information Technology 33(6): 561-573.

Philip J, Cherian V (2020) Impact of COVID-19 on Mental Health of the elderly. International Journal of Community Medicine and Public Health 7(6).

Qiu J, Shen B, Zhao M, Wang Z, Xie B, Xu Y (2020) A nationwide survey of psychological distress among Chinese people in the COVID-19 epidemic: implications and policy recommendations. General Psychiatry 33(2): e100213.

Rajkumar RP (2020) COVID-19 and mental health: a review of the existing literature. Asian Journal of Psychiatry 52(Aug): 102066.

Reger MA, Stanley IH, Joiner TE (2020) Suicide mortality and coronavirus disease 2019A perfect storm? JAMA Psychiatry 77(11): 1093-1094.

Riley C (2020, April 19) 60 Million European jobs are at risk from coronavirus. CNN Business.

Roy A (2020, April 3) The pandemic is a portal. The Financial Times.

Scerri J, Sammut A, Cilia Vincenti S, Grech P, Galea M, Scerri C, et al. (2021) Reaching out for help: calls to a mental health helpline prior to and during the COVID-19 pandemic. International Journal of Environmental Research and Public Health 18(9): 4505 .

Schonfeld L, Dupree LW (1994) Alcohol abuse among older adults. Reviews in Clinical Gerontology 4(3): 217-225. 
Van Jaarsveld GM (2020) The effects of COVID-19 among the elderly population: a case for closing the Digital Divide. Frontiers in Psychiatry (Nov).

Van Tilburg T, Steinmetz S, Stolte E, van der Roest H, de Vries DH (2020) Loneliness and mental health during COVID-19 Pandemic: a study among Dutch older adults. The Journal of Gerontology: Series B 76(7): e249-e255.

Webster P (2020) Virtual health care in the era of COVID-19. The Lancet 395(10231): 1180-1181.

World Health Organization - WHO (2022, January 11) Weekly epidemiological update. WHO. Available at: https://www.who.int/publications/m/item/weekly-epidemiologi cal-update-on-covid-19---11-january-2022.

Yang Y, Li W, Zhang Q, Zhang L, Cheung T, Xiang YT (2020) Mental health services for older adults in China during the COVID-19 outbreak. The Lancet Psychiatry 7(4): e19. 
